\title{
RESISTIR AOS CONHECIMENTOS CRISTALIZADOS PARA PRODUZIR OUTRAMENTOS NO CURRÍCULO
}

\author{
RESIST CRYSTALLIZED KNOWLEDGE TO PRODUCE OTHERING RESULTS IN THE CURRICULUM
}

Danilo Araujo de Oliveira' Anderson Ferrari

Resumo: Neste texto, inspirados na perspectiva póscrítica de currículo e em autoras/es pós-estruturalistas, buscamos explorar o funcionamento do currículo do grupo LGBTQI+ Resistência pela democracia, organizado no Facebook. Considerando a trama discursiva desse currículo e suas relações de saber-poder em torno das homossexualidades, mostramos que há uma convocação para pensar de outra forma para se tornar um sujeito, outro de si mesmo. Mobilizamos os ditos curriculares para evidenciar que há um investimento no outramento, na insistência do questionamento, sendo essa a dinâmica mais comum a esse currículo, ou seja, apostar muito mais nas perguntas que nas respostas, como uma forma de problematização, de levar os sujeitos a pensar e a agir de outra forma. Assim, o argumento principal desenvolvido no artigo é que as resistências, nesse currículo, acontecem quando se pode interpelar e mover o pensamento para conhecer de outra forma aquilo que já está posto, dado e na ordem do verdadeiro, o que, como efeito, possibilita o outramento. Dizemos então que nesse currículo não apenas se produz formas de conhecimento que implicam na demanda por um certo tipo de sujeito, mas, imediatamente, importa que esse sujeito esteja disposto a desconhecer.

Palavras-chave: currículo, resistência, outramento, homossexualidades.
Abstract: In this text, inspired by the post-critical perspective of curriculum and post-structuralist authors, we seek to explore the functioning of the LGBTQI + Resistance for Democracy group curriculum, organized on Facebook. Considering the discursive plot of this curriculum and its relations of knowledgepower around homosexualities, we show that there is a call to think in another way to become a subject other than himself. We mobilize the curricular sayings to show that there is an investment in the othering, in the insistence of questioning, this being the most common dynamic in this curriculum, that is, betting much more on the questions than on the answers, as a form of problematization, of taking the subjects to think and act differently. Thus, the main argument developed in the article is that resistances, in this curriculum, happen when it is possible to question and move thought in order to know in a different way what is already put, given and in the order of the true, which as an effect enables the other. We say then that this curriculum not only produces forms of knowledge that imply the demand for a certain type of subject, but, immediately, it implies that subject is willing to ignore it.

Keywords: curriculum, resistance, othering, homosexuality.

\section{INTRODUÇÃO}

Propositalmente, iniciamos o título deste artigo com a palavra "resistir". Resistir é um verbo que está diretamente ligado à ideia de construir, a uma certa inventividade da vida, dos sujeitos e dos conhecimentos. Mas não estamos nos referindo a qualquer ato de resistência. Queremos tomar como análise as possibilidades de existências inventadas para "resistir aos conhecimentos cristalizados" no que diz respeito às sexualidades e suas vinculações com os enquadramentos e as nomeações aos sujeitos. Tomada como "correlato da scientia sexualis"3, a sexualidade, a partir das análises de Michel Foucault

\footnotetext{
${ }^{1}$ Doutorando em Educação pelo Programa de Pós Graduação em Educação da Universidade Federal de Minas Gerais e membro do grupo de pesquisa Educação, Formação, Processo de Trabalho e Relações de Gênero, da Universidade Federal de Sergipe. E-mail: danilodinamarques@hotmail.com. Orcid: https://orcid.org/0000-0003-3222-3172.

${ }^{2}$ Professor adjunto da Faculdade de Educação e do Programa de Pós-graduação em Educação da Universidade Federal de Juiz de Fora. E-mail: aferrari13@globo.com. Orcid: https://orcid.org/0000-0002-5681-0753.

3 Foucault elabora o conceito de "scientia sexualis" para construir uma oposição com o que seria a "ars erotica" (arte erótica). A "ars erotica" seria própria de algumas civilizações como China e Índia, por exemplo, que seriam
} 
(1988), passou a ser entendida como um dispositivo, como resultado de práticas discursivas que foram capazes de criar verdades sobre o sexo, os desejos, os prazeres e os sujeitos. A sexualidade tem uma história, o que significa dizer que a história da sexualidade deve ser feita levando em consideração a história dos discursos e suas relações de saber-poder. Portanto, o convite que o autor nos faz é: "analisar a formação de um certo tipo de saber sobre o sexo, não em termos de repressão ou de lei, mas em termos de poder" (FOUCAULT, 1988, p. 88). O poder é entendido como um jogo que supõe resistências, lutas, enfrentamentos e disputas incessantes que são capazes de transformar os saberes, os poderes e os sujeitos, de maneira que ele - o poder - diz de uma correlação múltipla de forças. Resistir é uma força, parte do poder, como nos lembra Foucault (1988), o que demonstra o caráter relacional que constitui as correlações de força que "não podem existir senão em função de uma multiplicidade de pontos de resistência que representam, nas relações de poder, o papel do adversário, de alvo, de apoio, de saliência que permite a preensão"(FOUCAULT, 1988, p. 91).

Resistir é inventar, é produzir outras formas de ser e estar no mundo, é "outrar-se". Para Thaizy Bento (2013), "outrar-se" é um fenômeno revelado pela heteronímia de Fernando Pessoa, que foi capaz de criar e administrar diferentes "eus", com biografias distintas, de maneira que outramentos significa deixar-se contagiar pela novidade, por algo diferente e novo, deixando-se transformar-se em outras formas de ser e estar no mundo. Assim pensamos o currículo, atravessado por essas correlações de força, de maneira que estamos tratando de um campo do conhecimento que também tem uma história, que também é resultado de discursos, de relações saber-poder, de disputas e de resistências. Um currículo é capaz de produzir outramentos como formas de resistência. Assim, se estamos falando em "resistir aos conhecimentos cristalizados", no que diz respeito às sexualidades e suas nomeações aos sujeitos, estamos circunscrevendo nossa análise nas disputas no currículo e suas possibilidades de resistências, de invenção e de outramentos.

Nesse sentido, o verbo resistir adquire mais força em função dos ataques atuais que o campo das relações de gênero e sexualidade está enfrentando, muitos deles tomando o currículo como foco, como, por exemplo, a disputa acalorada que se deu em torno da inclusão ou exclusão dessas temáticas no Plano Nacional de Educação (PNE) e na Base Nacional Comum Curricular (BNCC). O momento atual nos exige coragem e posicionamento diante desses ataques, uma vez que fazemos parte dessas correlações de força que nos convocam a resistir, mas também a criar, como defende Marlucy Paraíso:

Como interromper os ataques que as escolas, os currículos e os temas do gênero, cultura afro, sexualidades estão sofrendo hoje no Brasil? Como introduzir nesse processo de ameaças e ataques, uma resistência que não somente "diga não", mas que também crie espaços possíveis nestes tempos de tantos retrocessos e de políticas reacionárias que querem impedir esses temas de estarem nas escolas, construindo outros sujeitos? Como afirmar a vida? (PARAÍsO, 2018, p.7).

A convocação é pela criação de espaços possíveis, capazes de criar outros sujeitos. O currículo é entendido como parte dessa rede de relações de saber-poder que constrói sujeitos e, portanto, como espaço de possibilidades de resistências e de criação. Não estamos entendendo currículo apenas como um conjunto de conhecimentos que precisa ser ensinado aos alunos na escola, operamos com o entendimento de currículo como discurso (PARAÍsO, 2007; SILVA, 1996). Discurso que, "ao corporificar narrativas particulares sobre o indivíduo e a sociedade, nos constitui como sujeitos" (SILVA, 1996, p. 195). Estamos lançando nosso olhar às muitas pedagogias que se constituem como um discurso para produzir sujeitos de determinadas maneiras e se desdobram em muitos artefatos culturais na contemporaneidade. Conforme ressaltado por Paraíso (2007, p. 24), "o nosso cotidiano nos expõe, nos ensina modos de ser, pensar, estar e agir, divulga conhecimentos sobre nós mesmos e sobre outras pessoas; demonstram valores, normas e procedimentos a serem adotados no nosso cotidiano". Assim, estamos considerando os diferentes desdobramentos curriculares em pedagogias em diferentes espaços e instâncias culturais.

sociedades com um entendimento e vivência da sexualidade ligada ao mistério e a determinados ritos de iniciação e aprendizado. A "scientia sexualis", por sua vez, seria algo próprio do ocidente moderno, centrado na busca por definir a sexualidade a partir dos parâmetros que operam com a inclusão do que é aceitável no campo da normalidade, e a exclusão do inaceitável. 
Assumindo essa concepção de currículo e de sexualidade como parte das relações de saber-poder que produz sujeitos, queremos colocar sob suspeita determinadas formas de saber, de maneira que possamos problematizar a dinâmica e a estruturação dessa rede de saber-poder-sexualidade-sujeito, para colocar sob investigação o funcionamento do poder implicado nas construções e nas resistências dos gêneros e da sexualidade. Para isso, vamos focar no ciberespaço do Facebook, onde um grupo de mais 320.000 pessoas compartilha diariamente fatos, dúvidas, suposições, afirmações sobre suas vidas com outras pessoas de diversas partes do Brasil e do mundo. O grupo em questão é o LGBTQI+ Resistência pela democracia, um grupo fechado no Facebook, que estamos entendendo como currículo. Mesmo que o nome do grupo se refira a toda comunidade que o nomeia, estabelecemos um recorte em torno das homossexualidades masculinas para definir o foco deste artigo: analisar as resistências que aparecem nesse currículo a respeito das "verdades" do sujeito homossexual. Como jovens gays reelaboram um conhecimento sobre si mesmos no currículo de um grupo fechado do Facebook? Como esse currículo do grupo abre todo um campo de resistência aos conhecimentos que estão na ordem da verdade?

\section{HOMOSSEXUALIDADES COMO RESISTÊNCIAS E OUTRAMENTOS}

Para entender o currículo de um grupo no Facebook como espaço de construção de resistência e de possibilidade de outramentos, é importante recuperar o entendimento de homossexualidade que marca a constituição dos sujeitos, homossexuais ou não, visto que o discurso das homossexualidades, sendo relacional, atinge a todos, inclusive as heterossexualidades, entendidas como seu oposto. A internet é, hoje em dia, esse lugar em que o debate em torno do que é a homossexualidade ganha força. Segundo Bulter (2018), as manifestações representam a entrada do "corpo repudiado" na esfera pública. As homossexualidades, durante muito tempo, representaram esse corpo repudiado e, para muitas expressões das homossexualidades, ainda hoje, a aparição em público significa ameaça à vida. A resistência está na simples existência e reafirmação da sua forma de vida, de se apresentar em público. Não estamos falando somente de estar na rua, mas de se organizar em grupos na internet como forma de se apresentar em público, visto que é nesse espaço que existe a ligação entre outras pessoas. O corpo privado condiciona o corpo público, de maneira que eles não são completamente distintos (BUTLER, 2018). A internet e o Facebook são esses espaços que passaram a ser entendidos como de produção e circulação de grupos, de manifestação, de enunciados de resistência, organizando e dando vida a situações de enfrentamento, lutas políticas e defesas de formas de ser e estar no mundo.

O Facebook é entendido como esse espaço contemporâneo de produção dos sujeitos, onde aprendemos a namorar, encontramos parceiros sexuais, construímos nossas redes de pertencimento, nos manifestamos politicamente, protestamos, enfim, construímos formas de existência (EVANGELISTA, 2016; OLIVEIRA, FERRARI, MACHADO, 2019). Como em muitas ocasiões não há necessidade de se apresentar visualmente, é um espaço que nos fornece um certo sentido de segurança, sobretudo em se tratando da relação com a homossexualidade e suas possibilidades de apresentação e paquera. Esse espaço de resistência e outramentos dialoga com outros que também ensinam os sujeitos a se nomearem e a se constituirem como são.

É o que foi retratado na série Elite ${ }^{4}$, uma dessas séries das plataformas de streaming que coloca em pauta, na sociedade ocidental, uma variedade de temáticas da contemporaneidade que constroem um sentido para o que classificamos como "juventude", tais como os relacionamentos amorosos, o envolvimento com drogas e diversão, os conflitos na escola e os enquadramentos sexuais. Uma série ambientada na Espanha, tomando como cenário central uma escola de classe alta que recebe três bolsistas de outra classe social menos favorecida. Para desenvolver o enredo central da trama, que é o assassinato de uma jovem do núcleo rico, os autores recorrem à construção de um conjunto de outros dramas que vão dando sentido às relações entre os jovens. Um desses dramas, que queremos trazer aqui, diz da relação entre dois jovens meninos que se envolvem num relacionamento homossexual. Omar e

4 Série original Netflix (2018). Criação: Carlos Montero e Darío Madrona. O enredo da série parte da transferência de três jovens da escola pública para um conceituado colégio de elite, o conflito entre classes acaba levando a um assassinato. Disponível em https://www.netflix.com/br/title/80200942. 
Ander são jovens de classes sociais e religião distintas (sendo Omar muçulmano) que se conhecem através de um aplicativo de namoro gay. Os encontros são marcados pela excitação dos jovens por estarem juntos, misturada pelo conflito de se identificarem como homossexuais.

Num desses encontros, os dois protagonizam uma cena que queremos tomar como provocativa para iniciar algumas discussões que propomos fazer neste texto sobre os saberes cristalizados da homossexualidade e as possibilidades de outramentos no currículo. A família e os amigos dos rapazes supõem que eles são heterossexuais, mas eles se encontram às escondidas e começam a vivenciar um relacionamento. Ander convida Omar para ir à sua casa e, no desenrolar dessa visita, numa excitante cena de sexo, Omar dispara o seguinte questionamento a Ander: "Sabe quais são as perguntas que os gays fazem quando se conhecem? A primeira é essa: quando soube que gostava de caras? A segunda é: seus pais sabem?" Como Omar já tinha feito a primeira pergunta para Ander, ele faz a segunda, ao que Ander apenas responde: "Sabe de uma coisa? Eu te amo".

Duas perguntas que transformam a cena em situações de ensinar e aprender a sermos homossexuais ou não. São perguntas que parecem caber somente para os homossexuais, já que ninguém, comumente, pergunta aos meninos heterossexuais quando começaram a gostar de meninas e tampouco se os pais sabem dessa preferência afetivo-sexual. A cena e as perguntas nos fazem pensar sobre os saberes que definem as homossexualidades, mas também podemos questionar sobre a importância desse mecanismo de produção dos sujeitos que é a mídia, como nos convida Paraíso.

Realmente a mídia, em seus diferentes meios e produções (rádio, televisão, revistas, jornais, publicidade, cinema e todos os veículos massivos de informação, incluindo a internet), é uma moda, uma aspiração, uma reivindicação. Ela invade o nosso cotidiano, nos expõe, nos ensina modos de ser, pensar, estar e agir, divulga conhecimentos sobre nós mesmos e sobre outras pessoas; demonstram valores, normas e procedimentos a serem adotados no nosso cotidiano. Ela produz sentidos, práticas e sujeitos de um determinado tipo; faz com que desejemos coisas, muda as nossas percepções, nos modela e nos seduz (PARAísO, 2007, p. 24).

A cena em questão pode trazer uma série de elementos analíticos no que se refere à constituição das subjetividades em relação à sexualidade. No entanto, queremos nos deter em alguns aspectos como disparadores para apresentar a problemática que iremos explorar. Primeiramente, é preciso levar em conta que não existe sujeito a priori, ou seja, dado e constituído antes daquilo que foi inventando como verdade. Pelo contrário, até mesmo antes do nosso nascimento, estamos em contato com um mundo já organizado por discursos, saberes e verdade que irão disputar a produção de determinados tipos de sujeitos. A primeira pergunta anunciada por Omar - "quando você soube que gostava de caras?" - nos aproxima de uma discussão que atravessa as obras de Foucault no que se refere à relação entre sexualidade, saberes, verdade e subjetividades, relação que diz dos modos como nos tornamos sujeitos. O questionamento feito pode anunciar que o que se está tomando como parâmetro é a heterossexualidade, essa que majoritariamente, no discurso normativo - que vem se atualizando desde o século XIX -, se organiza como a forma autorizada e "única" de viver os prazeres e os desejos. Nesse sentido, um outro saber que difere desse dado, constituído, implica um movimento de descoberta. Ou seja, enquanto a heterossexualidade, discursivamente produzida como "natural" e não questionável, funciona na nossa sociedade como a regra, o movimento de vivência das sexualidades dissidentes é esse de se perceber como "o outro", o que implica essa relação de "descobrir-se" diferente. Todavia, o que é preciso considerar, aqui, é que, ainda que a pergunta talvez leve a entender que essa descoberta pode ser dada de uma vez por todas, como se houvesse uma sexualidade lá a ser desvendada, isso é um processo longo permeado por relações de saber-poder que vão nos dizendo o que é ser um sujeito de uma sexualidade.

As duas questões levantadas pelos personagens da série - "Quando soube que gostava de caras? Seus pais sabem?" - não são uma ficção, elas povoam o imaginário dos sujeitos, homossexuais ou não, visto que, desde a modernidade, fomos aprendendo a confessar e a construir um saber sobre os nossos desejos para, assim, "saber" quem somos, nos nomear. "Quando soube que gostava de caras?" revela uma certa ruptura, a busca pela origem de um desejo e, portanto, por uma classificação, como se isso fosse possível de ser definido. Mas também revela o que seria um rito de passagem. Mas, mais importante 
que a resposta, nos parece que é a relação de pertencimento que é construída entre os dois personagens e que nos permite abandonar a série para pensar nesses processos de pertencimentos como definidores das homossexualidades. A homossexualidade é algo que se ensina e se aprende, sobretudo pelas histórias compartilhadas entre os iguais, como se todos os homossexuais passassem pelas mesmas experiências de "revelação", “confissão" e "aceitação". Tanto que há uma segunda pergunta que dialoga com a primeira e com esse sentido de homossexualidade como algo que se revela. Revela-se porque há o pressuposto social de que todos somos heterossexuais, de maneira que ser homossexual necessita de uma revelação. Nesse sentido, nos parece possível pensar as homossexualidades como resistência desse modelo normativo da heterossexualidade e, portanto, como um "outramento", um processo de se tornar um outro de si mesmo.

No Brasil há um certo embaralhamento entre gênero e sexualidade, de forma que ser homem é ser heterossexual, o que nos possibilita dizer que o sentido de "normalidade" dos gêneros está diretamente ligado à construção, reafirmação e manutenção das heterossexualidades. Mas a heterossexualidade não é algo natural, tampouco um regime fechado em si mesmo, único e coerente. Ela é construção discursiva e relacional, além de ser incoerente e apresentar fissuras, abrindo brechas para as resistências, para as subversões que são construídas a partir da norma. É essa necessidade de repetição que marca a construção dos gêneros e das heterossexualidades que possibilita as resistências, os "outramentos" de gênero e sexualidade. As homossexualidades, sempre no plural, dada a impossibilidade de se afirmar um homossexual típico ou homogêneo, é, desde sua origem, uma "invenção discursiva", uma forma de resistência, visto que é uma subversão ao sistema da heterossexualidade como norma. As homossexualidades podem ser experimentadas e assumidas a partir de múltiplos saberes, relações e práticas, constituindo-se como uma resistência aos discursos cristalizados, possibilitando que outros sujeitos inventem outras formas de resistir e de contestar.

O que as duas questões dos meninos da série nos provocam, para além dessa produção de ficção, é que os discursos das homossexualidades, aquilo que se diz e que se cala sobre elas é, hoje, uma possibilidade de se questionar sobre o campo da sexualidade a partir de outras perspectivas, como, por exemplo, a teoria queer. Uma teoria que não está interessada em descobrir a causa das homossexualidades, mas que toma esses discursos sobre ela para questionar a naturalidade e os discursos que produziram a heterossexualidade como norma, colocando sob suspeita essas formas de saber como "verdade" única. Dessa forma, também dão lugar aos discursos que silenciaram outras formas de ser e estar no mundo, nomeando e enquadrando essas formas como não naturais ou mesmo anormais. As homossexualidades se constituem como uma mudança de perspectiva, como possibilidade de se construir como outro de forma positiva.

Nesse sentido, podemos dizer que as homossexualidades estão envolvidas nos processos de subjetivação. Os processos de subjetivação, ou mais especificamente, a construção do sujeito homossexual, esse tornar-se gay, é heterogênea, múltipla, plural, de maneira que cada um se torna gay de determinada maneira, a partir das experiências que vai vivendo ao longo da vida, ou até mesmo das aproximações e distanciamentos de determinados discursos que vão dizendo sobre o que é ser homossexual, e o que são as homossexualidades. Essas aproximações acontecem em diversos espaços e até mesmo no ciberespaço, como aconteceu com o próprio casal de Elite que se conhece em um desses aplicativos de namoro, que também são um espaço de constituição de sujeitos gays, pois lá circulam discursos os quais demandam certos tipos de sujeitos.

\section{LGBTQI+ RESISTÊNCIA PELA DEMOCRACIA: um currículo pelo outramento}

Interessa-nos tomar o grupo organizado no Facebook LGBTQI+ Resistência pela democracia como espaço e como grupo, seguindo a definição de Butler (2018), que defende que, diante da precariedade que nos ameaça, o exercício público do gênero ou mesmo das sexualidades já é um movimento social, visto que, para que aconteça esse exercício, depende que ocorram ligações entre as pessoas. Os jovens desse grupo utilizam uma linguagem específica da internet articulada com um vocabulário compartilhado 
entre pessoas LGBTQI+ ${ }^{5}$ (Lésbicas, Gays, Bissexuais, Transexuais, Travestis, Queer e Intersexo), a qual, atrelada a outros elementos, como, por exemplo, indicação de filmes para assistir, lugares para frequentar, quais políticos apoiar, pode evidenciar a existência de uma cultura própria em funcionamento nesse ciberespaço.

O simples fato de fazer parte desse grupo já coloca duas redes de pertencimentos. O primeiro é o pertencimento a alguma das letras que nomeiam os sujeitos: LGBTQI+. Ser homossexual é uma construção de pertencimento, que, nos dias de hoje, significa participar de redes de sociabilidade gay, dentre elas, grupos na internet. A outra rede de pertencimento que se constitui na participação deste grupo é o posicionamento em defesa da resistência. Não se trata de um grupo gay qualquer, mas de um grupo gay que assume a postura da resistência pela democracia, colocando-se politicamente contra o governo atual e toda série de medidas que mantém a LGBTQIfobia como característica da sociedade brasileira.

A emergência do grupo se dá em um contexto de crescentes ameaças aos direitos já conquistados das pessoas LGBTQI+ nas últimas eleições presidenciais no Brasil. As afirmações preconceituosas do então presidente contribuíram para a mobilização das pessoas para participação nesse grupo. Ao participar desse grupo, percebemos que está em circulação, na linha do tempo, uma série de verdades mantendo o movimento de contestação e reiteração, de maneira que essa manutenção vai criando uma aliança em torno da precariedade que as pessoas LGBTQI+ têm em comum. Nesse sentido, podem-se encontrar algumas enunciações de questionamento a muitas verdades que constituem as pessoas consideradas abjetas, anormais:

[1] (...) infelizmente a construção de masculinidade numa sociedade machista acaba afetando e muito os homens trans também. Eles acabam inconscientemente forçados à uma masculina tóxica para serem reconhecidos como homens.

[2] Sim, concordo... Infelizmente o machismo já está implantado demais na sociedade, mas sempre esperamos que alguém que faz parte de uma minoria consiga desconstruir esse pensamento ao menos um pouco, só que não é o caso dele...

[3]N vale acreditar q o homem veio do barro e usar a biologia para ser transfobico ok

[4] Família n, pq isso n pode ser chamado de família primeiramente! Família é aquela que apoia, que independente de qualquer raça, cor, orientao sexual tem o propósito de uma verdadeira família "amor" e se n pode amar um filho por ser gay me desculpe, mas $\mathrm{n}$ passa apenas de um casal de adultos juntos! (em relação a uma família que devolve jovem ao abrigo por saber que ele era gay)

Entendemos que essas afirmações podem provocar rupturas nos conhecimentos cristalizados e constituem o modo como nós percebemos e percebemos o outro. As três primeiras enunciações destacadas evidenciam que uma construção normativa de gênero incide sobre os sujeitos LGBTQI+ e o termo infelizmente usado infere como isso não fosse considerado bom para muitas vidas, de modo que a segundo dito afirma: esperamos que alguém que faz parte de uma minoria consiga desconstruir esse pensamento. Constituir-se como minoria é compartilhar de uma precariedade que o torna menor, precário, daí a necessidade de formar uma aliança e de construir um conhecimento outro para ver de outra forma. Da mesma forma, é acionado aqui um outro entendimento de família. O post em que encontramos esse dito dizia sobre uma família adotativa que devolvera um jovem após descobrir que era gay $^{6}$. Abriu-se um campo de discussão acerca do entendimento de família, que serviu para discutir e

\footnotetext{
${ }^{5} \mathrm{~A}$ linguagem específica da internet à qual fazemos referência é a abreviação de palavras diversas, utilização de memes para se comunicar e recursos disponibilizados na própria plataforma como curtir e compartilhar. Quanto ao vocabulário compartilhado por pessoas LGBTQI+, podemos citar alguns que aparecem no grupo: sapão, chocada, exatamentchy, 'as bonitas', achar cool, uó, diva. Para mais detalhes sobre o vocabulário a que fazemos menção, ver: Pajubá: o código linguístico da comunidade LGBT (BARROSO, 2017), O percurso semântico de alguns vocábulos do pajubá: gírias faladas pelas bichas (NETTO JUNIOR, 2018).

${ }^{6}$ Para mais detalhes, ver: https://observatoriog.bol.uol.com.br/noticias/comportamento/2020/01/familia-devolvejovem-ao-abrigo-apos-descobrir-que-ele-era-gay-confira-
} 
desconstruir um sentido de família como ligada ao pai e mãe natural, o que se configura como família no entendimento de família heterossexual normativa, acusada de contribuir para exclusão de muitas vidas, como a do jovem gay novamente abandonado.

Nesse grupo, prescreve-se como os participantes devem ser, conduzir-se, comportar-se. No que se refere a essa condução de si, são interditados comportamentos preconceituosos, orienta-se como procurar um profissional de saúde: Um aviso super importante pra uma galera preconceituosa que tem pelo grupo!; Serve como um alerta importante p q tenhamos cuidado com os profissionais a quem confiamos a nossa saúde mental. Alguns valores aparecem mais recorrentes que outros. É comum também localizar uma rivalidade entre o certo e o errado. Muitas das postagens tomam um direcionamento de buscar a opinião das pessoas sobre determinado assunto como, por exemplo, o que pensam sobre homens fantasiados de mulher no carnaval, sobre relação entre pessoas sorodiscordantes. Convoca-se os jovens a discutir sobre gênero, sexualidade, política, entretenimento, mídia, cultura. Os temas são bastante variados e as opiniões também, resultado de um grupo em que várias questões atravessam os interesses de seus participantes, fazendo com que o grupo tenha um movimento intenso de discussão. Essas observações nos levaram a entender, a partir do referencial teórico adotado neste artigo, que esse grupo se constitui um currículo. E este é um processo marcado por disputas, em meio a relações de poder-saber que incidem diretamente nos modos como esses sujeitos estão se constituindo.

As resistências, nesse currículo, acontecem, quando se pode interpelar e mover o pensamento para conhecer de outra forma aquilo que já está posto, dado e na ordem do verdadeiro, o que, como efeito, possibilita o outramento. Nesse sentido, como destacamos anteriormente, quando uma das enunciações do grupo aponta "esperamos que alguém que faz parte de uma minoria consiga desconstruir esse pensamento", ou ainda quando uma determinado postagem indaga "qualquer tipo de fantasia que brinque com a identidade de gênero é ofensiva?, ou ainda "vocês acham que brancos e negros são desejados na mesma proporção? Vocês acham que o loirinho rico de corpo malhado é tão desejado quanto a bicha da favela? convoca-se, nesse currículo, a pensar de outra forma para se tornar um sujeito outro de si mesmo. O investimento desse currículo pelo outramento está na insistência do questionamento, sendo essa a dinâmica mais comum ao grupo, ou seja, apostar muito mais nas perguntas que nas respostas, como uma forma de problematização, de levar os participantes a pensar e a agir de outra forma.

O outramento deriva do verbo outrar-se, palavra cunhada por Fernando Pessoa para se referir a um processo de distanciamento de si, para se tornar outro (BENTO, 2013). Trata-se, assim, de um afastamento, desprezo, desapego de um eu para se fazer novo. Nesse sentido, podemos dizer que a discussão do currículo em funcionamento no grupo LGBTQI+, que as resistências que nele emergem se aproximam de um trabalho crítico do pensamento sobre o próprio pensamento, tal qual ressaltado por Foucault, que afirma que o esse trabalho consiste em tentar saber de que maneira e até onde seria possível pensar diferentemente, em vez de legitimar o que já se sabe (FOUCAULT, 1984). Os descaminhos daquilo que se conhece insurgem nesse currículo, o que nos leva a concordar com o fato deque "existem momentos na vida em que a questão de saber se se pode pensar diferentemente do que se pensa, e perceber diferentemente do que se vê, é indispensável para continuar a olhar ou a refletir" (FOUCAULT, 1984, p. 13).

Mesmo com as diversas transformações ao longo dos anos, "na segunda década do século XXI, a rua segue perigosa para aqueles que desejam pessoas do mesmo sexo" (PELÚCIO, 2017, p. 8). É nesse contexto de medo das ruas e continuado investimento da heterossexualidade como modo saudável e normal sobre as vidas que a internet se torna uma importante possibilidade para viver as homossexualidades como uma estética da existência e como um modo de vida que resiste. A internet ampliou as possibilidades de aliança, de sociabilidade e de pertencimento entre os sujeitos, dando origem a diferentes grupos que lutam por apoio social e reivindicam uma nova forma de fazer política. Essa forma

historia?utm_source=Facebook\&utm_medium=social\&utm_campaign=FB obsg\&fbclid=IwAR2G_ZpMrMwpf7B93u2zRHvPnGI_R1VBqVkZRn1TT41OP7yO35leZeDXOTI Acesso em: 22 jan. 2020 
de luta, por sua novidade, constitui sua própria forma social.

O que significa, então, aparecer na política contemporânea? E podemos considerar essa questão de alguma forma sem recorrer à mídia? Quando fazemos uma consideração sobre o que é aparecer, concluímos que aparecemos para alguém e que o nosso aparecimento tem que ser registrado pelos sentidos, não apenas os nossos, mas os de alguém mais (BUTLER, 2018, p. 95).

O direito de aparecer diz da afirmação da vida, da afirmação de que a vida dos homossexuais importa. Essa aparição e constituição do grupo dizem de um processo de ensinar e aprender. Nessa perspectiva, estamos entendendo que cada grupo formado no Facebook se constitui como currículo, pois aí estão em circulação saberes diversos, com capacidades variadas, muitos sentidos e possibilidades que incidem sobre os processos de subjetivação dos sujeitos (PARAísO, 2009). O grupo forma um composto heterogêneo cheio de ordenamentos, quereres (CORAZZA, 2001), mas também é "um artefato com muitas possibilidades de diálogos com a vida; com diversas possibilidades de modos de vida, de povos e de seus desejos. É um artefato com um mundo a explorar" (PARAísO, 2009, p. 278).

Somos nós também, por meio de relações sociais, que movimentamos os currículos, entramos na disputa por significados outros que possam emergir entre aqueles pensados e possíveis. Dessa forma, "numa perspectiva menos topológica, menos segmentada, da dinâmica social, poderemos, quem sabe, ver também a cultura e o currículo como relações sociais" (SILVA, 2001, p. 21). Isso porque "produzimos significados, procuramos obter efeitos de sentido, no interior de grupos sociais, em relação com outros indivíduos e com outros grupos sociais" (SILVA, 2001, p. 21).

Não são simplesmente relações sociais que estão em funcionamento nesse grupo, mas aquilo que Silva (2001) chama de relações sociais de poder. A produção de sentido em torno das homossexualidades e do que é ser homossexual, nesse currículo, são assimétricas:

[1] Da pra traçar um perfil do tipo de gay que acha que esse assunto é piada?

[2] Pegou as padrão no pulo

[3] Bixa foi UO, depois perguntam pq pegamos tanto no pé delas, as padronizadas!

[4] Desde quando ser afeminado é ridículo? Não Vó brincadeira ofensiva a gays, os únicos que se sentiram ofendidos foram os cristãos por uma representatividade de um Jesus gay

[5] Quem se sente ofendido só pode ser gay "padrão e fora do meio". O Porta dos Fundos não ridiculariza nenhum veado, só mostra um dos vários tipos de gay afeminado: debochado, estravagante, sem medo de expor sua sexualidade... Nada a ver esse texto!

A postagem a que esses comentários estão relacionados é sobre o filme especial de Natal do Porta dos Fundos7 que supõe que Jesus é gay em sua narrativa. No entanto, alguns comentários versam sobre como alguns modos de viver a homossexualidade ainda são discriminados entre os próprios homossexuais. Assim, há um tensionamento na homonormatividade que atravessa esse currículo, de modo que a ação de muitos gays homonormativos, aqui chamados de "padrão", não é autorizada. Ao mesmo tempo, uma das postagens afirma que há "vários tipos de gays" e a discussão mostra que alguns são mais aceitos do que os outros e quais são abominados no currículo investigado: aqueles que não aceitam os corpos que não se conformam ao gênero designado.

Percebe-se que diversos discursos disputam, de forma desigual, aquilo que se pretende afirmar como verdadeiro, como legítimo em torno dessas questões e de como vivê-las. Assim, "relações de poder são, ao mesmo tempo, resultado e origem do processo de significação" (SILVA, 2001, p. 23). Nesse sentido, aquilo que circula nesse grupo e tem por objetivo conduzir os sujeitos de determinadas formas,

\footnotetext{
7 Porta dos Fundos é uma produtora de vídeos voltados para o humor e comédia, veiculados na internet, principalmente no canal YouTube. Uma produtora criada em 2013 e que hoje é um dos canais mais visualizados no Brasil. Todo final de ano a produtora veicula um "Especial de Natal” tomando as histórias bíblicas como provocadora para a comédia. No ano de 2019, o "Especial de Natal” girou em torno da suposta homossexualidade de Jesus Cristo, o que causou grande polêmica na sociedade.
} 
disponibilizar posições para que os indivíduos ocupem, não deve ser compreendido como a verdade, mas como ditos que têm pretensões de verdade, que estão no jogo do verdadeiro e do falso. São relações de forças que estão em luta para que determinados significados pareçam hegemônicos, predominem em detrimento dos demais, sejam reiterados e se multipliquem para ganharem um efeito de verdade. No entanto, podemos localizar nessa luta também

[...] o caráter incerto, indeterminado, incontido do processo de significação, [que] por sua vez, faz com que o resultado dessa luta não seja, nunca, garantido, previsível. As relações de poder dirigem o processo de significação; elas, entretanto, não o esgotam, não o realizam plenamente (SILVA, 2001, p. 23).

Dessa forma, até os significados mais aparentes, naturalizados, incrustados, serão, de alguma maneira, contestados, negociados, estarão em processo de transformação. São essas possibilidades que permitem afirmar que o currículo é "um composto heterogêneo, constituído por matérias díspares e de naturezas distintas; por saberes diversos e com capacidades variadas; por sentidos múltiplos e com inúmeras possibilidades" (PARAÍSO, 2009, p. 278). É possível dizer, então, que é próprio do currículo esse caráter de contestação, conflito e de disputa. Por mais que ele tenha por objetivo os enquadramentos, as normalizações e os ordenamentos, as escapatórias são possíveis nesse processo, pois o currículo também pode ser entendido como "um artefato com muitas possibilidades de diálogos com a vida; com diversas possibilidades de modos de vida, de povos e de seus desejos. É um artefato com um mundo a explorar" (PARAÍSO, 2009, p. 278). Focando no currículo desse grupo fechado do Facebook, composto de jovens homossexuais masculinos, o que podemos questionar é: quais são os ordenamentos, os enquadramentos e quais subjetividades são demandadas nesse ciberespaço? Mas, ao mesmo tempo, que outras possibilidades e insurgências surgem nesse contexto?

Dizemos, então, que esse currículo não apenas produz formas de conhecimento que implicam a demanda por um certo tipo de sujeito, mas, imediatamente, implicam que esse sujeito esteja disposto a desconhecer. Parece que há, nesse currículo, "um esforço contínuo para desvincular o eu da normalidade, para que ele possa ser algo mais do que aquilo que a ordem das coisas prediz" (BRITZMAN, 1996, p. 73). Esse é um movimento de separação, de distanciamento das muitas normas que ainda organizam o modo como se vê a homossexualidade e a disputa que se trava aqui revela seu caráter instável, mutável e volátil. Nesse processo, chama atenção o fato de que, para resistir, seja preciso que toda forma de conhecimento seja rearranjada, desestabilizada e desfeita.

Nesse sentido, acionamos Foucault, quando diz que devemos compreender que, "com nossos desejos, por meio deles, instauram-se novas formas de relações, novas formas de amor e novas formas de criação" (FOUCAULT, 2004, p. 260). O que significa que uma vida criativa, um novo modo de vida só emerge a partir das problematizações que levantamos sobre nós mesmos acerca daquilo que nos define, nos captura e nos aprisiona. Parece-nos que há, nas fendas desse currículo, uma pedagogia que não está presa ao conhecimento que está posto, já construído, ao mesmo tempo em que anseia por outras formas de conhecimento e, conjuntamente e, ao mesmo tempo, cobiça um outro sujeito. O sujeito desse currículo é, pois, um sujeito que questiona constantemente sobre tudo aquilo que organiza a si mesmo e sua sexualidade.

Nessa perspectiva, o currículo em funcionamento no grupo LGBTQI+ pela resistência não apenas define aquele conhecimento que deve ser desestabilizado e, logo, traz a possibilidade de um conhecimento outro, mas constitui o sujeito que emerge a partir desse conhecimento outro. $O$ que nos chama atenção aqui é que, embora subordinadas, as homossexualidades não precisam e não devem ser vividas como estereótipos. Pelo contrário, a partir do currículo que aqui investigamos, reiteramos que "é absolutamente necessário que os prazeres do desejo, esta coisa chamada amor, sejam considerados em seus próprios termos, em termos que falam algo mais do que sofrer a punição dos discursos dominantes" (BRITZMAN, 1996, p. 89).

Essa outra forma de conhecimento que emerge no currículo LGBTQI+ pela resistência pode trazer de volta a relação entre conhecimento e ignorância ressaltada por Eve Sedgwick (1990). Conhecer de 
outra forma diz de uma relação com nossa própria ignorância, que é, ela mesma, um efeito do conhecimento que está posto. Entrar em contato com aquilo que ignoramos é uma resistência àquilo que se toma como correto no regime de discursivo em que estamos inseridos. Consideramos, pois, que nos constituímos sujeitos a partir dos discursos que consideramos verdadeiros, vinculando-nos a eles e fazendo deles a nossa própria verdade. Problematizar esses discursos diz da problematização de nós mesmos como sujeitos e da possibilidade de aceder a uma vida criativa.

Considerando que "o currículo produz, o currículo nos produz" (SILVA, 2001, p. 27) a partir dos discursos que ele faz circular como verdadeiros, de modo que ele está engajado no percurso de nossas vidas "na constituição de um caminho, de um trajeto de conhecimento que é necessário percorrer ao longo da vida" (ZAGO, 2016, p. 116), dizemos que o currículo em funcionamento no grupo LGBTQI+ pela resistência, longe de se contentar em propor um percurso, pretende abrir caminhos. Uma dessas rotas que se abre é acerca do modo como vemos, no âmbito das relações gays, as pessoas portadoras do HIV. Em uma das postagens, abre-se o seguinte questionamento: Como contar ao meu parceiro que vivo com hiv? Aliás devo?

Sabe-se que se constituiu um discurso na epidemia de AIDS dos anos 1980 que vinculou HIV e AIDS à homossexualidade, de modo que a própria homossexualidade passou a ser sinônimo de doença, instaurando, assim, uma série de preconceitos que só dificultou e atrasou que medidas eficazes pudessem ser tomadas. Muitas pessoas na época morreram, criou-se um pânico moral em torno das relações entre pessoas do mesmo sexo, de modo que, mesmo após 30 de epidemia, com tratamentos eficientes, as marcas mais fortes que permanecem até hoje, talvez, sejam o preconceito. Assim, estabelecer um relacionamento com um soropositivo seja ainda algo temoroso, tenso e intranquilo para muitas pessoas. Isso diz do conhecimento que temos sobre o HIV, mas diz também das nossas ignorâncias. No currículo do grupo LGBTQI+ pela resistência, há uma inquietação em relação a essa forma de conhecimento, de modo que se incita que os sujeitos (des)conheçam aquilo que está na ordem do verdadeiro. A partir de um post de um participante reclamando sobre o tratamento aos homossexuais, inicia-se um debate em torno do poder do conhecimento como transformador de condutas. Diz o jovem:

Pregam o tempo inteiro que a sociedade é ignorante, mas vivem na própria ignorância e se recusam a ter empatia em troca de viver no próprio egocentrismo e pensando no próprio umbigo. Vocês não se informam e ficam fazendo auê sobre a vida de outras pessoas, igualzinho à sociedade que tanto criticam. Melhorem.

O post parece direcionado a alguém, não um alguém específico, mas aos homossexuais individualmente que constituem o grupo no coletivo: "Pregam o tempo inteiro que a sociedade é ignorante..." Destinada ao grupo, a frase é uma acusação, ao mesmo tempo em que é uma denúncia de um grupo que acusa a sociedade de ser "ignorante", mas que, segundo o jovem, também vive na "ignorância". O jogo de acusação está em torno da disputa de conhecimento: "Vocês não se informam e ficam fazendo auê sobre a vida de outras pessoas, igualzinho à sociedade que tanto criticam". É uma acusação e uma denúncia, mas também é um investimento no outro, uma tentativa de transformar o grupo naquilo que ele quer que os outros sejam e como gostaria que se comportassem, a partir de maior informação, apostando que o saber é capaz de modificar os sujeitos. Um outro jovem responde, mantendo a lógica da informação e da transformação pelo conhecimento.

Vão lá assistir "Carta para além dos muros", tá muito bem feito e talvez ajude algumas mentes a mudarem alguma coisa. Porque tá difícil...

obrigado por mostrar seu ponto de vista e de abrir pra discussão, estive conversando recentemente com um amigo sobre o tema e acho que vai ajudar a gente a discutir com mais informação

Como são constituídos por relações de poder, outros discursos entrecruzam esse currículo disputando o conhecimento que se pretende produzir. Mas há um investimento para que outro regime de verdade se abra e componha esse currículo. No primeiro comentário da postagem em questão, há uma provocação em torno da ignorância em que muitos nós escolhemos ficar, ao nos inscrevermos em determinada inteligibilidade acerca do HIV ou, mais especificamente, acerca de ter relações sorodiscordantes. Contornar essas concepções e rearticular nosso modo de conhecer são necessidades 
para se desvincular do preconceito. A segunda enunciação que outorga que todos/as assistam ao documentário "Carta para além dos muros" 8 reitera essa necessidade para a mudança, o que depende de que se alterem os esquemas de inteligibilidade a partir dos quais pensamos nossa existência que só pode emergir, quando rearranjamos nossa relação com a verdade. O documentário citado aposta também na produção de verdades outras sobre o HIV, contando sua longa história e os bastidores para mostrar como a ignorância acerca do vírus produziu muitas mortes e como é importante e necessário torcer aquilo que nos foi dito para criar outras epistemologias que afirmem a vida.

Desses trechos emergem um outramento, que induzem a modos específicos de tessituras curriculares para produzir novos caminhos. Nessas irrupções reside não somente uma convocação a conhecer formas outras, como também a se constituir num outro sujeito. Nesse sentido, reafirmarmos aqui como um currículo pode ganhar forma como um daqueles "recursos [que] devemos possuir para trazer para a comunidade humana aqueles humanos que não foram considerados parte do reconhecidamente humano" (BUTLER, 2004, p. 225). O grupo como um currículo nos convida a pensar nas possibilidades de resistência ligadas a um sentido de revolta aos conhecimentos cristalizados. Em todo o artigo, aproximamo-nos da perspectiva foucaultiana do saber-poder para pensar nessas resistências e, mantendo essa aproximação, é importante recuperar o ensinamento do autor de que os poderes não são absolutamente absolutos. Com isso, queremos chamar atenção para o fato de que, por trás dos conhecimentos cristalizados sobre as homossexualidades e para além das ameaças e violências que nos atingem, sempre existirão as possibilidades das insurgências, das revoltas e das resistências dos sujeitos. Acreditamos que são essas revoltas e resistências dos sujeitos contra os saberes-poderes tidos como valorizados, "naturais", "dados" e aceitos que animam as transformações, dando vida aos outramentos, a outras formas de conhecer, de apender e de ensinar, a outras formas de ser e estar no mundo.

\section{CONSIDERAÇÕES FINAIS}

Nessas considerações finais é importante recuperar o título do artigo e, com ele, as duas ideias que organizaram nosso investimento de análise: "resistir aos conhecimentos cristalizados para produzir outramentos no currículo". Primeiramente, investimos na ideia de "resistir aos conhecimentos cristalizados". Trata-se de se posicionar diante do que é tido como conhecimento, daquilo que foi construído historicamente como saberes em torno das homossexualidades, o que sabemos sobre os sujeitos, seus desejos, seus corpos, enfim, uma rede de saberes que nos leva às aceitações e coerções que fizemos conosco mesmos e com os outros. Mas, nesses saberes, também estão presentes os caminhos para as resistências, quase como uma revolta pelo que são capazes de fazer conosco e pelo que somos capazes de fazer com os outros a partir deles. São essas resistências como revoltas, como formas de nos insurgir contra os conhecimentos cristalizados, que dão vida aos sujeitos e aquilo que chamamos de realidade. Mas "resistir aos conhecimentos cristalizados" não é uma ideia sozinha, ela diz de um complemento, de uma finalidade: "para produzir outramentos no currículo". Estamos tratando de resistências "para" alguma coisa, "para” algum caminho, "para" produzir outramentos.

Essa é a força do nosso artigo, ou seja, estamos apostando na produção de outras formas de ser e estar no mundo. E estamos apostando nessa produção a partir da perspectiva da problematização. Foucault (2006, p. 228), relacionando problematização com política, define problematização: “ou seja, da elaboração de um domínio de fatos, práticas e pensamentos que me parecem colocar problemas para a política". Problematizar tem a ver com a história do pensamento, uma vez que o que pensamos e as formas como agimos a partir do que pensamos dizem de maneiras de pensar e agir historicamente construídos. Nesse sentido, problematizar significa investir em colocar sob suspeita nossas formas de saber, pensar e agir. A produção de outramentos diz desse investimento na problematização, como é

\footnotetext{
8 "Cartas para além dos muros" é um documentário dirigido por André Canto e lançado no Brasil em setembro de 2019. O documentário conta a trajetória do HIV/Aids no Brasil através de entrevistas com médicos, ativistas e pacientes, além de se utilizar de um vasto material de arquivo que ajuda a contar essa história, desde o pavor inicia à epidemia até o período de conscientização.
} 
conduzido pelos participantes do grupo, ou seja, a aposta desses sujeitos é se incomodar com aquilo que está posto para provocar novas formas de pensar, agir e saber.

Contudo, não estamos trabalhando com a produção de outramentos em qualquer espaço. Nosso campo de análise diz do espaço do Facebook e, mais especificamente, de um grupo LGBTQI+ fechado, entendendo-o como um currículo em que os sujeitos investem nas problematizações dos saberes para se colocarem sob investigação, para se transformarem e modificarem o outro, construindo um jeito resistente de estar no mundo e de pensar os saberes que nos dão lugares neste mundo. Mais do que a proposta de uma nova e "única" posição de sujeito, os sujeitos, com seus posts, sugerem um movimento, uma disposição para resistir e explorar as fraturas nos saberes dominantes.

\section{REFERÊNCIAS}

BARROSO, Renato Regis. Pajubá: o código linguístico da comunidade LGBT. PPGLA Dissertação. Programa de Pós-Graduação Stricto Sensu em Letras e Artes. Manaus. Amazonas. 2017.

BENTO, Thaizy Cristhine Salles. Fernando Pessoa: alteridade e outramento. Faculdade de Filosofia, Letras e Ciências Humanas, São Paulo: Universidade de São Paulo, 2013.

BUTLER, Judith. Corpos em aliança e a política das ruas: notas para uma teoria performativa de assembleia. Rio de Janeiro: Civilização Brasileira, 2018.

BUTLER, Judith. Undoing gender. New York: Routledge, 2004b.

BRITZMAN, Deborah. O que é essa coisa chamada amor - identidade homossexual, educação e currículo. Educação e Realidade, vol, 21, nº1, jan./jun. p.71-96, 1996

CORAZZA, Sandra Mara. O que quer um currículo? Pesquisas pós-críticas em educação. São Paulo: Vozes, 2001.

EVANGELISTA, Gislene Rangel. \#CurrículodoFacebook: denúncia da crise e demanda pela reforma do Ensino Médio na linha do tempo da escola. 2016. Dissertação (Mestrado em Educação) - Pós-graduação em Educação: Conhecimento e Inclusão Social. Universidade Federal de Minas Gerais. $188 \mathrm{f}$.

FOUCAULT, Michel. História da Sexualidade II. O uso dos prazeres. Rio de Janeiro: Edições Graal, 1984. . História da sexualidade l: a vontade de saber. Rio de Janeiro: Edições Graal, 1988.

. Polêmica, Política e Problematizações. In: FOUCAULT, Michel. Ética, sexualidade, política. Rio de Janeiro: Forense Universitária, 2006.

."Sexo, poder e a política da identidade". Verve - Revista do Nu-Sol, nº 5, p. 260-277, 2004.

NETTO JUNIOR, Neurivan Gonçalves. O percurso semântico de alguns vocábulos do pajubá: gírias faladas pelas bichas. 2018. $17 \mathrm{f}$. Trabalho de Conclusão de Curso (Licenciatura em Letras - Português) Universidade de Brasília, Brasília, 2018.

PARAÍSO, Marlucy Alves. Currículo e mídia educativa brasileira: poder, saber e subjetivação. Chapecó: Argos, 2007.

. Currículo, desejo e experiência. Educação e Realidade. Mai/Ago. 2009.

. Gênero, sexualidade e heterotopia: entre esgotamentos e possibilidades nos currículos. In: RIBEIRO, Paula Regina Costa (et al.). Corpo, gênero e sexualidade: resistência e ocupa(ações) nos espaços de educação. Rio Grande: Ed. FURG, 2018, p. 7-28.

PELÚCIO, Larissa. Um flerte com a normalidade. In: MISKOLCI, Richard. Desejos digitais: uma análise sociológica da busca por parceiros on-line. Belo Horizonte: Autêntica. 2017.

OLIVEIRA, Danilo Araujo de.; FERRARI, Anderson.; MACHADO, Nathalye Nallon. "Ninguém solta a mão de ninguém”: conectados/as em rede, resistimos. Práxis Educativa, Ponta Grossa, v. 14, n. 2, p. 659 -677, maio/ago.

2019. DOI: https://doi.org/10.5212/praxeduc.v.14n2.014 
ISSN $1983-1579$

Doi: 10.22478/ufpb.1983-1579.2020v13n1.50417

http://periodicos.ufpb.br/ojs2/index.php

SEDGWICK, Eve Kosofsky. The Epistemology of The Closet. Berkeley: The University of California Press, 1990.

SILVA, Tomaz Tadeu da. Terminais: as transformações na política da pedagogia e na pedagogia da política. Petrópolis: Vozes, 1996.

SILVA, Tomaz Tadeu da. O currículo como fetiche: a poética e a política do texto curricular. Belo Horizonte: Autêntica, 2001

ZAGO, Luiz Felipe. Gênero, sexualidade e corpo-currículo na sociabilidade de um site de relacionamentos gay. Em Aberto, Brasília, v. 29, n. 95, p. 109-120, jan./abr. 2016.

Recebido em: 25 de janeiro de 2020

Aceito em: 29 de março de 2020

Publicado em: 25 de abril de 2020 